\title{
Implante imediato associado à infecção periapical crônica: relato de caso clinico
}

\author{
Immediate implant associated with chronic periapical infection: \\ clinical case report \\ Implante inmediato asociado a la infección periapical crónica: \\ relato de caso clinico \\ Thiago Borges MATTOS 1 \\ Felipe Campos MENDES 2 \\ Thaís Yumi Umeda SUZUKI ${ }^{3}$ \\ Jéssica Lemos GULINELLI ${ }^{2}$ \\ Paola Ferreira GALITO ${ }^{4}$ \\ Pâmela Leticia dos SANTOS ${ }^{5}$ \\ ${ }^{1}$ Faculdade do Centro Oeste Paulista, FACOP, 17490-000 Juiz de Fora-MG, Brasil. \\ ${ }^{2}$ Faculdade de Odontologia, USC Univ. Sagrado Coração, 17011-160 Bauru - SP, Brasil \\ ${ }^{3}$ Departamento de Odontologia Restauradora, Faculdade de Odontologia, UFMG Universidade Federal de Minas Gerais \\ 31270-901 Belo Horizonte-MG, Brasil \\ ${ }^{4}$ Cirurgiã-Dentista, 27570-000 Porto Real-RJ, Brasil \\ ${ }^{5}$ Departamento de Ciências da Saúde, Faculdade de Odontologia, UNIARA Universidade de Araraquara, \\ 14801-340 Araraquara - SP Brasil
}

\section{Resumo}

A busca por novas técnicas cirúrgicas preservando a integridade dos tecidos periodontais associado à reabilitação com implantes dentários favorece a qualidade estética e funcional, garantindo assim a satisfação dos pacientes. O objetivo do trabalho foi demonstrar a reabilitação com implante imediato em alvéolo com infecção associado a provisionalização imediata e proservação de 36 meses após a reabilitação final. Paciente apresentou-se com elemento 24 com mobilidade grau III, defeitos ósseos ao redor do dente, drenagem purulenta e bolsa profunda à sondagem de $(>7 \mathrm{~mm})$. Foi utilizado o protocolo de regeneração óssea guiada (ROG) com o substituto ósseo para preenchimento do "gap" entre o implante e o osso alveolar, com o uso de tela de titânio para ganho ósseo vertical e horizontal e membranas autólogas de fibrina obtidas através do processo de centrifugação e preparo. Após o período de osseointegração, foram realizados procedimentos de moldagem personalizada para a reabilitação final com prótese metalocerâmica. No período de 36 meses de acompanhamento clínico e radiográfico não há sintomatologia dolorosa, infecção, mobilidade do implante e perda óssea peri-implantar acentuada. O paciente apresentou-se satisfeito com relação à estética e função protética.

Descritores: Infecção; Implantes Dentários; Reabilitação Oral.

\begin{abstract}
The search for new surgical techniques preserving the integrity of the periodontal tissues associated to the rehabilitation with dental implants, aiming at the aesthetic and functional quality, thus guaranteeing the satisfaction of our patients, has been much studied in modern dentistry. The aim of our study was to describe a clinical case of an oral rehabilitation using a dental implant installed immediately post-dental extraction of element 24, presenting grade III mobility, bone defects around the tooth, purulent drainage, and deep pocket to $>7 \mathrm{~mm}$ ). The guided bone regeneration protocol (ROG) was used as a bone substitute to fill the gap between the implant and the alveolar bone and to supply the bone defects with the use of a titanium screen for vertical and horizontal bone gain and membranes autologous fibrin (PRF), obtained through the centrifugation and preparation process. After the period of osseointegration, the prosthetic part was followed up to complete the case. Following the protocols of the applied methodology, the patient presents with 3 years of follow-up, satisfied and without painful symptomatology.

Descriptors: Infection; Dental Implants; Oral Reabilitation.
\end{abstract}

\section{Resumen}

La búsqueda de nuevas técnicas quirúrgicas preservando la integridad de los tejidos periodontal asociados a la rehabilitación con implantes dentales favorece la calidad estética y funcional, garantizando así la satisfacción de los pacientes. El objetivo del trabajo fue demostrar la rehabilitación con implante inmediato en alvéolo con infección asociada a la provisión inmediata y la proservación de 36 meses después de la rehabilitación final. El paciente se presentó con elemento 24 con movilidad grado III, defectos óseos alrededor del diente, drenaje purulento y bolsa profunda al sondeo de $(>7 \mathrm{~mm})$. Se utilizó el protocolo de regeneración ósea guiada (ROG) con el sustituto óseo para rellenar el "gap" entre el implante y el hueso alveolar, con el uso de pantalla de titanio para ganancia ósea vertical y horizontal y membranas autólogas de fibrina obtenidas a través del proceso de centrifugado y preparación. Después del período de osseointegración, se realizaron procedimientos de moldeado personalizado para la rehabilitación final con prótesis metalocerámica. En el período de 36 meses de seguimiento clínico y radiográfico no hay sintomatología dolorosa, infección, movilidad del implante y pérdida ósea peri-implantar acentuada. El paciente se presentó satisfecho con relación a la estética y función protética.

Descriptores: Infección; Implantes Dentales; Rehabilitación Bucal.

\section{INTRODUÇÃO}

$\mathrm{Na}$ implantodontia moderna, o processo de reparo ósseo após a instalação de implante imediato em um elemento dentário com lesão crônica, não se diferencia em relação à qualidade e ao tempo de osseointegração de locais onde não haviam lesões ${ }^{1-3}$.

Antes de avaliar a viabilidade desse procedimento é essencial a indicação adequada da instalação de implante imediato em área infectada, sendo as patologias mais comuns: dentes com falhas irreversíveis no tratamento endodôntico, doença periodontal avançada, fraturas radiculares, cáries avançadas abaixo da margem gengival, e reabsorção interna e/ou externa ${ }^{3-6}$.

Essa técnica acarreta em vantagens incluindo, a redução do número de procedimentos cirúrgicos, preservação da espessura óssea alveolar e da dimensão do tecido mole, o reparo ósseo ocorre simultaneamente a osseointegração, minimizando os danos biológicos durante esse processo. Também não ocorre indução de aumento de taxas de complicações, o que favorece uma maior integridade dos tecidos moles e duros ${ }^{7}$.

No entanto, a principal questão controversa na literatura atual, é se a instalação de implantes em sitio infectado traria a perda do mesmo. A resposta dessa pergunta se tornou uma incógnita e alvo de muitos estudos como este (Quadro 1). O essencial para o tratamento dessas áreas, previamente a instalação do implante é a realização dos procedimentos clínicos perioperatórios sejam cuidadosamente realizados, tais como, administração de antibióticos e a limpeza meticulosa (curetagem) do alvéolo ${ }^{10,17}$.

Adicionalmente, para o sucesso da instalação de 
implantes imediatos é necessário o contato efetivo do osso alveolar com o implante dentário, em casos de defeitos ósseos peri-implantares, é indicado o uso de biomateriais para estabelecer a neoformação óssea e auxiliar o reparo ósseo. Os enxertos ósseos usados para preencher o defeito peri-implantar podem ser autógenos, heterógeno, homógenos e aloplásticos ${ }^{23}$.

Quadro 1. Revisão da literatura contendo os principais estudos sobre a instalação de implantes dentários em área com infecção

\begin{tabular}{|c|c|c|c|c|c|c|}
\hline Autor/Ano & $\begin{array}{l}\text { Tipo de } \\
\text { artigo }\end{array}$ & Grupos & $\begin{array}{l}\text { Tipo de } \\
\text { Patologia }\end{array}$ & $\begin{array}{l}\text { Métodos de } \\
\text { avaliação }\end{array}$ & $\begin{array}{l}\text { Período } \\
\text { (meses) }\end{array}$ & Conclusão \\
\hline Bell et al., $2011^{8}$ & $\begin{array}{l}\text { Estudo } \\
\text { retrospectivo }\end{array}$ & $\begin{array}{l}\text { * Com lesão }(n= \\
285) \\
\text { * Sem lesão }(n= \\
637)\end{array}$ & $\begin{array}{l}\text { Periapical } \\
\text { crônica }\end{array}$ & $\begin{array}{l}\text { Clínico e } \\
\text { Radiográfico }\end{array}$ & $\begin{array}{l}19.75 \\
\text { (média) }\end{array}$ & $\begin{array}{l}\text { A instalação de implantes em áreas infectadas por patologia } \\
\text { periapical crônica pode ser considerado uma opção de tratamento } \\
\text { seguro e viável. }\end{array}$ \\
\hline Casap et al., $2007^{9}$ & $\begin{array}{c}\text { Estudo } \\
\text { Retrospectivo }\end{array}$ & Lesão (n=30) & $\begin{array}{l}\text { Periodontal } \\
\text { e/ou Periapical } \\
\text { crônica }\end{array}$ & $\begin{array}{c}\text { Clínico e } \\
\text { Radiográfico }\end{array}$ & 72 & $\begin{array}{l}\text { Os implantes imediatos são uma opção de tratamento viável } \\
\text { em pacientes com infecções dentoalveolares. }\end{array}$ \\
\hline Crespi et al., $2010^{10}$ & $\begin{array}{l}\text { Estudo } \\
\text { Prospectivo }\end{array}$ & $\begin{array}{l}{ }^{*} \text { Com Lesão } \\
(n=15) \\
{ }^{*} \text { Sem Lesão } \\
(n=15)\end{array}$ & Periapical & $\begin{array}{c}\text { Clínico e } \\
\text { Radiográfico }\end{array}$ & 24 & $\begin{array}{l}\text { Os implantes instalados imediatamente em locais de extração } \\
\text { afetados por infecção tornou-se igualmente favorável, revelando um } \\
\text { resultado previsível. }\end{array}$ \\
\hline Crespi et al., $2010^{11}$ & $\begin{array}{l}\text { Estudo } \\
\text { Prospectivo }\end{array}$ & $\begin{array}{l}\text { *Com Lesão } \\
(\mathrm{n}=197) \\
{ }^{*} \text { Sem Lesão } \\
(\mathrm{n}=78)\end{array}$ & Periapical & $\begin{array}{c}\text { Clínico e } \\
\text { Radiográfico }\end{array}$ & 48 & $\begin{array}{c}\text { Os implantes dentários que foram colocados e imediatamente } \\
\text { submetidos à carga protética, em regiões periodontalmente } \\
\text { infectadas não apresentaram diferenças significativas aos implantes } \\
\text { colocados em locais não infectados, em relação ao índice de } \\
\text { sucesso. }\end{array}$ \\
\hline $\begin{array}{l}\text { Del Fabbro et al., } \\
2009^{12}\end{array}$ & $\begin{array}{l}\text { Estudo } \\
\text { Prospectivo }\end{array}$ & Lesão (n=61) & $\begin{array}{l}\text { Periapical } \\
\text { Crônica }\end{array}$ & $\begin{array}{l}\text { Clínico e } \\
\text { Radiográfico }\end{array}$ & 18,5 & $\begin{array}{l}\text { O uso de PRF combinado com um procedimento imediato de } \\
\text { instalação de implantes pode ser considerado uma opção de } \\
\text { tratamento segura, eficaz e previsível para a reabilitação de alveolos } \\
\text { infectados. }\end{array}$ \\
\hline Deng et al., $2010^{13}$ & $\begin{array}{l}\text { Estudo } \\
\text { prospectivo }\end{array}$ & Lesão (n=84) & Periapical & $\begin{array}{c}\text { Clínico e } \\
\text { Radiográfico }\end{array}$ & 12 & $\begin{array}{l}\text { O índice de insucesso foi maior na região maxila pós-extração. Isso } \\
\text { indica um risco aumentado de falha para implantes imediatos } \\
\text { instalados em maxilas periodontalmente comprometidas. }\end{array}$ \\
\hline Fugazzotto, $2012^{14}$ & $\begin{array}{l}\text { Estudo } \\
\text { Retrospectivo }\end{array}$ & Lesão (n=418) & Periapical & $\begin{array}{l}\text { Clínico e } \\
\text { Radiográfico }\end{array}$ & 67,3 & $\begin{array}{l}\text { Implantes instalados imediatamente em sítios que demonstraram } \\
\text { patologia periapical produziram resultados semelhantes aos } \\
\text { imediatamente colocados em sítios pristinos. A diferença nas taxas } \\
\text { de sobrevivência não foi estatisticamente significativa. }\end{array}$ \\
\hline Jung et al., $2013^{15}$ & $\begin{array}{l}\text { Estudo } \\
\text { Prospectivo }\end{array}$ & $\begin{array}{l}\text { *Com lesão }(n=12) \\
\text { *Sem lesão }(n=15)\end{array}$ & Periapical & $\begin{array}{c}\text { Clínico e } \\
\text { Radiográfico }\end{array}$ & 60 & $\begin{array}{l}\text { A substituição de dentes com patologias periapicais por implantes } \\
\text { instalados imediatamente após a extração dentária pode ser uma } \\
\text { modalidade de tratamento bem sucedida. }\end{array}$ \\
\hline $\begin{array}{l}\text { Kadhemi et al., } \\
\qquad 2013^{16}\end{array}$ & $\begin{array}{c}\text { Estudo } \\
\text { Retrospectivo }\end{array}$ & Lesão $(n=18)$ & Periapical & $\begin{array}{c}\text { Clínico e } \\
\text { Radiográfico }\end{array}$ & 3 meses & $\begin{array}{l}\text { A instalação de implantes dentários } \\
\text { no local de lesões periapicais resultantes de infecções podem não } \\
\text { ter qualquer efeito negativo sobre o sucesso geral dos implantes. }\end{array}$ \\
\hline $\begin{array}{l}\text { Lindeboom et al., } \\
\qquad 2006^{17}\end{array}$ & $\begin{array}{l}\text { Estudo } \\
\text { Prospectivo }\end{array}$ & Lesão $(n=50)$ & Periapical & $\begin{array}{c}\text { Clínico e } \\
\text { Radiográfico }\end{array}$ & 12 & $\begin{array}{l}\text { A instalação de implante imediata em alvéolos com lesões } \\
\text { periapicais crônicas pode ser indicada. }\end{array}$ \\
\hline $\begin{array}{l}\text { Marconcini et al., } \\
2013^{18}\end{array}$ & $\begin{array}{l}\text { Estudo } \\
\text { retrospectivo }\end{array}$ & Lesão (n=20) & Periapical & $\begin{array}{c}\text { Clínico e } \\
\text { Radiográfico }\end{array}$ & 12 & $\begin{array}{l}\text { A instalação de implantes em alvéolos frescos infectados pode ser } \\
\text { uma técnica operatória válida que conduz a resultados previsíveis } \\
\text { se forem realizados cuidados pré-operatórios e pós-operatórios } \\
\text { adequados. }\end{array}$ \\
\hline Naves et al., $2009^{19}$ & Caso Clínico & Lesão ( $n=3$ ) & $\begin{array}{l}\text { Periapical } \\
\text { Crônica }\end{array}$ & $\begin{array}{l}\text { Clínico e } \\
\text { Radiográfico }\end{array}$ & 36 & $\begin{array}{c}\text { A instalação imediata do implante combinada com regeneração } \\
\text { óssea guiada pode ser indicada para substituição de dentes } \\
\text { perdidos por lesões periapicais crônicas com história de falha } \\
\text { endodôntica na maxila anterior. }\end{array}$ \\
\hline $\begin{array}{l}\text { Siegenthaler et al., } \\
2007^{20}\end{array}$ & $\begin{array}{l}\text { Estudo } \\
\text { Prospectivo }\end{array}$ & $\begin{array}{l}\text { *Sem lesão }(n=17) \\
\quad{ }^{*} \text { Com lesão } \\
(n=17)\end{array}$ & Periapical & $\begin{array}{c}\text { Clínico e } \\
\text { Radiográfico }\end{array}$ & 12 & $\begin{array}{l}\text { Os implantes imediatos instalados em alvéolos que possuem } \\
\text { patologia periapical apresentaram-se reposta igual em relação a } \\
\text { tecido mole e duro aos implantes do grupo sem lesão. }\end{array}$ \\
\hline $\begin{array}{c}\text { Truninger et al., } \\
2011^{21}\end{array}$ & $\begin{array}{c}\text { Estudo } \\
\text { Prospectivo }\end{array}$ & $\begin{array}{l}\text { *Com lesão }(n=13) \\
\text { *Sem lesão }(n=16)\end{array}$ & Periapical & $\begin{array}{c}\text { Clínico e } \\
\text { Radiográfico }\end{array}$ & 36 & $\begin{array}{l}\text { A instalação imediata de implantes em locais com } \\
\text { patologias periapicais podem ser uma modalidade de tratamento } \\
\text { bem-sucedida. }\end{array}$ \\
\hline Villa et al., $2005^{22}$ & $\begin{array}{l}\text { Estudo } \\
\text { Prospectivo }\end{array}$ & Lesão (n=101) & Periapical & $\begin{array}{c}\text { Clínico e } \\
\text { Radiográfico }\end{array}$ & 44 & $\begin{array}{l}\text { Alta taxa de sobrevivência pode ser alcançada para implantes } \\
\text { imediatos e carregados precocemente na mandíbula, em sítios } \\
\text { infectados. }\end{array}$ \\
\hline
\end{tabular}

Além da estabilidade primaria igual ou superior a $40 \mathrm{~N}^{24,25}$ e a realização de exodontia atraumática com uso de periótomos e extratores, evitando possíveis danos ás paredes ósseas remanescentes ${ }^{3,26,27}$, outro fator a considerar é a carga imediata, em implantes instalados imediatamente após extrações, para isso deve-se observar alguns fatores para o sucesso, incluindo: desenho da superfície do implante que otimize o travamento; passividade da prótese e componentes instalados e estabilidade oclusal ${ }^{4,28}$.

A carga imediata caracteriza-se pela ativação protética de implantes em até 48 horas após inserção, instalados em condições ideais de estabilidade primária, evitando assim a micromovimentação vinda de forças laterais ${ }^{25,29,30}$.

Seu uso em relação à carga tradicional traz como vantagem a manutenção da forma essencial do tecido mole, em particular das papilas interproximais, maximizando os resultados estéticos ${ }^{11}$. O uso de provisório está associado à manutenção do perfil de emergência do dente extraído, à preservação da arquitetura óssea e gengival, promovendo benefício psicológico e satisfação estética e funcional para o paciente pi, $^{3,26,27,31-33}$

Necessidades atuais na implantodontia moderna conduz ao clínico especializado vencer desafios em áreas estéticas como a colocação de implantes pós-extração em alvéolos com lesão periapical e imediata provisionalização do mesmo. O objetivo do presente trabalho foi demostrar a reabilitação com implante imediato em alvéolo com infecção crônica associada à provisionalização imediata e preservação de 36 meses de acompanhamento após a reabilitação final, demonstrando que é possível seguindo um planejamento adequado fundamentado na literatura vigente para garantir a previsibilidade estética e funcional no longo prazo.

\section{CASO CLÍNICO}

Paciente do gênero feminino, 36 anos de idade, procurou clínica particular com queixa de mobilidade e sensação dolorosa no dente 24 (Figura 1). Ao exame clínico foi constatada mobilidade grau III do elemento 24, com drenagem de secreção purulenta e bolsa profunda à sondagem (>7mm). Para completo diagnóstico foi solicitada tomografia computadorizada (TC) do elemento em questão, por meio da qual pode-se constatar a presença de defeito ósseo ao redor do dente (Figura 2).

Após analise do caso e informado sobre todas as 
alternativas de tratamento, optou-se pela realização da reabilitação dentoalveolar imediata com implantes osseointegrados e regeneração óssea guiada (ROG), com auxílio de tela de titânio para ganho ósseo vertical e horizontal e membranas autólogas de fibrina (PRF), obtida através do processo de centrifugação e preparo.

Duas semanas antes do procedimento cirúrgico, foi realizado procedimentos de raspagem e alisamento radicular para melhora da saúde periodontal. Para iniciar o procedimento cirúrgico, foi realizado a antissepsia intra e extrabucal com clorexidina $0,12 \%$, e em seguida a anestesia dos nervos infra-orbitário, alveolar superior posterior e palatino maior do lado esquerdo, com articaína 4\% com adrenalina 1:200.000.

Após a anestesia da região, foi realizada a incisão de Nowak, com as relaxantes entre a distal do elemento dentário 22 e mesial do 26, foi usado descolador de molt para o descolamento mucúperiosteal e acesso a área cirúrgica. A exodontia foi realizada com auxílio de um periótomo, seguido de curetagem de todo tecido de granulação com cureta serrilhada, buscando remover todos fragmentos residuais que pudessem interferir no processo de neoformação óssea e propiciar o sangramento do tecido ósseo remanescente.

A fresagem foi realizada seguindo todo protocolo para instalação do implante AXIOM PX (Anthogyr/France), seguindo $\mathrm{o}$ posicionamento tridimensional do implante visando a manutenção do espaço biológico. Como previsto o implante ficou com $5 \mathrm{~mm}$ de exposição em todas as paredes devido ao defeito pré-existente (Figura 3). Para solucionar esse defeito ósseo, foi confeccionado um template com chumbo de película radiográfica para a correta modelação da tela de titânio a ser colocada no alvéolo. Após a verificação do correto formato do molde foi feito o recorte da tela de titânio (Bionnovation-biomedical) e assim conforme o planejamento para propiciação da regeneração óssea guiada foi inserido uma mistura de PRF (Fibrina Rica em Plaquetas) e OBM (Bonefill Media) preenchendo todo o defeito ósseo.

Após a inserção do substituto ósseo foi realizada a aposição da tela de titânio (Figura 4) e colocação de membranas de PRF como barreira biológica. As suturas foram realizadas com Nylon 5.0 (Figura 5). Um provisório foi confeccionado seguindo os princípios de regeneração tecidual guiada, visando um bom perfil de emergência da prótese.

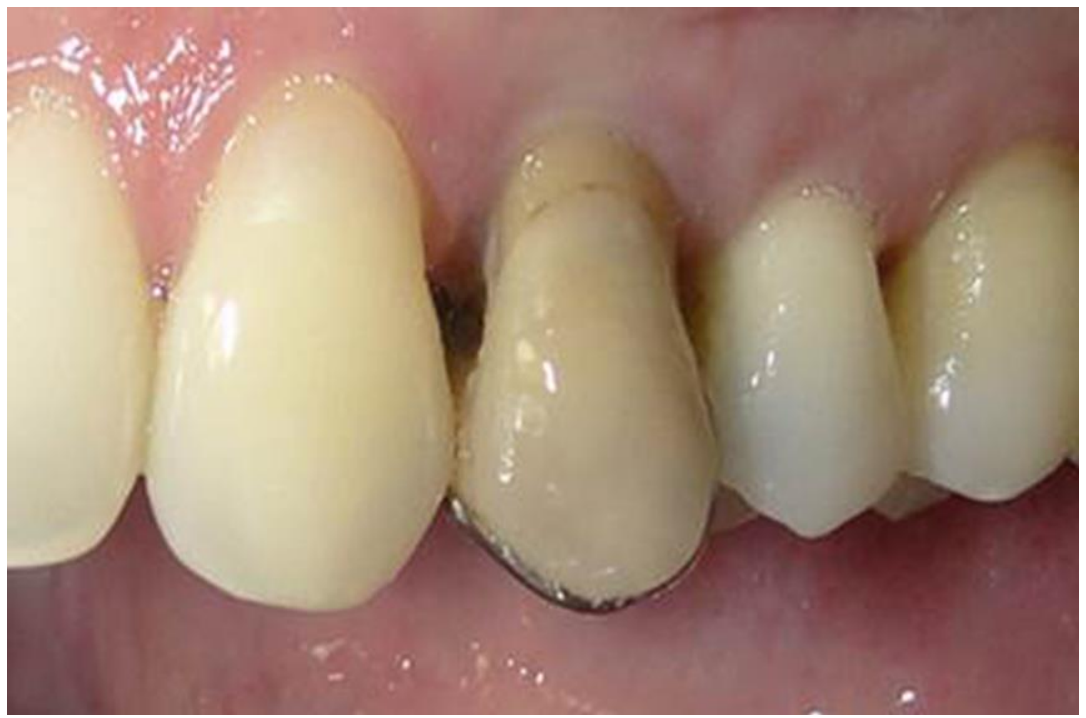

Figura 1: Avaliação clínica inicial.

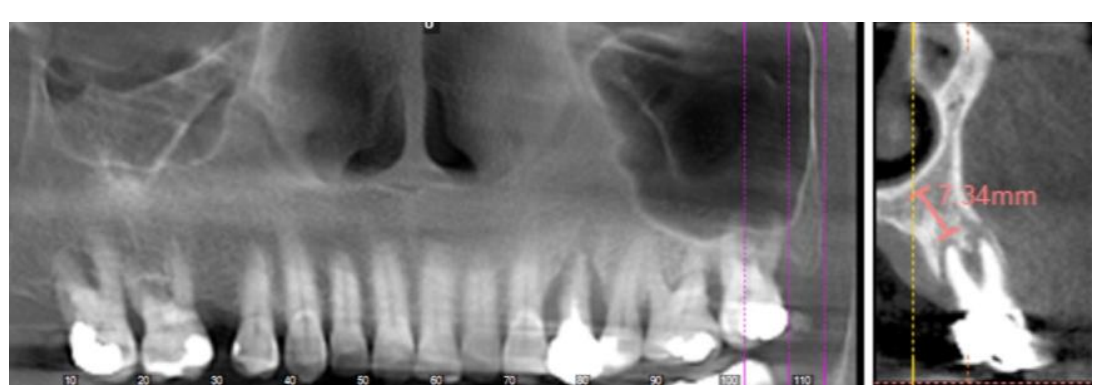

Figura 2: Avaliação de imagem inicial. Nota-se a reabsorção óssea vertical associada ao dente 24 .

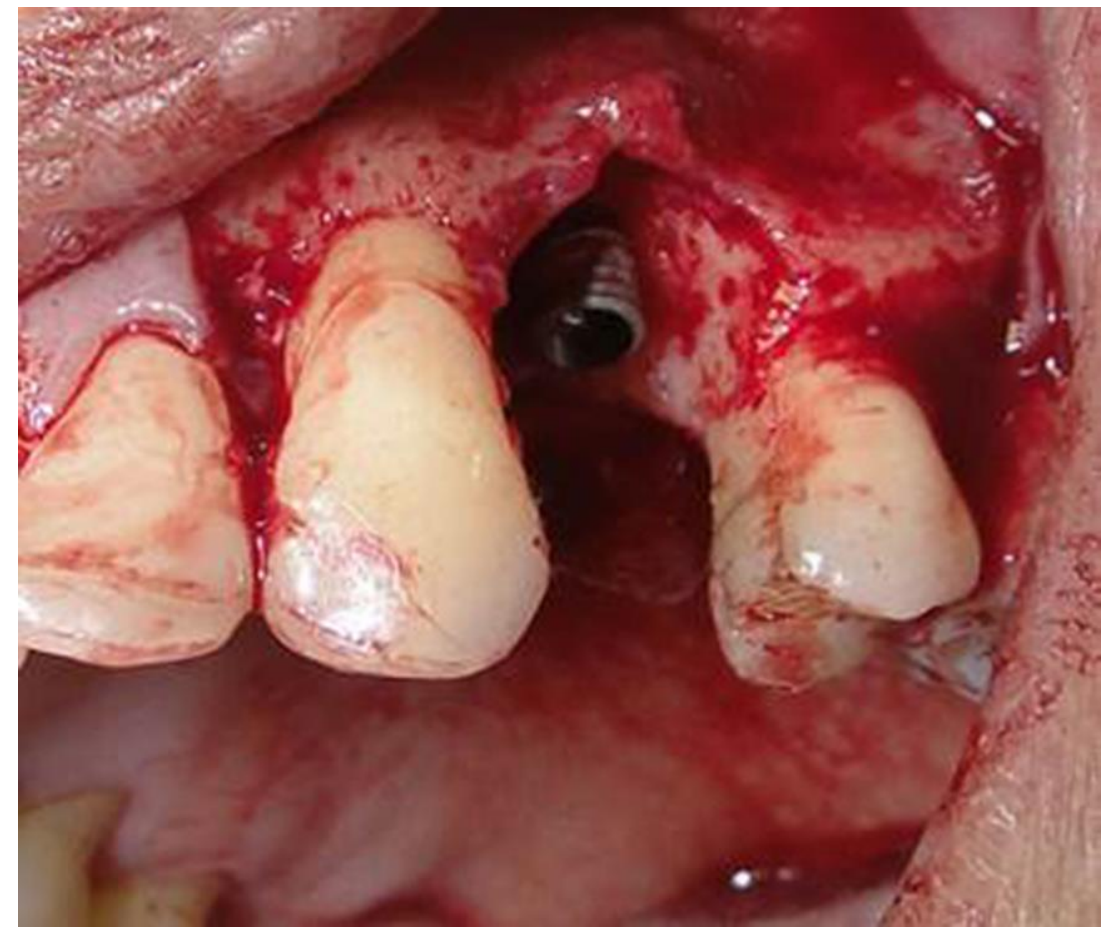

Figura 3: Implante instalado. Nota-se a presença do defeito ósseo.

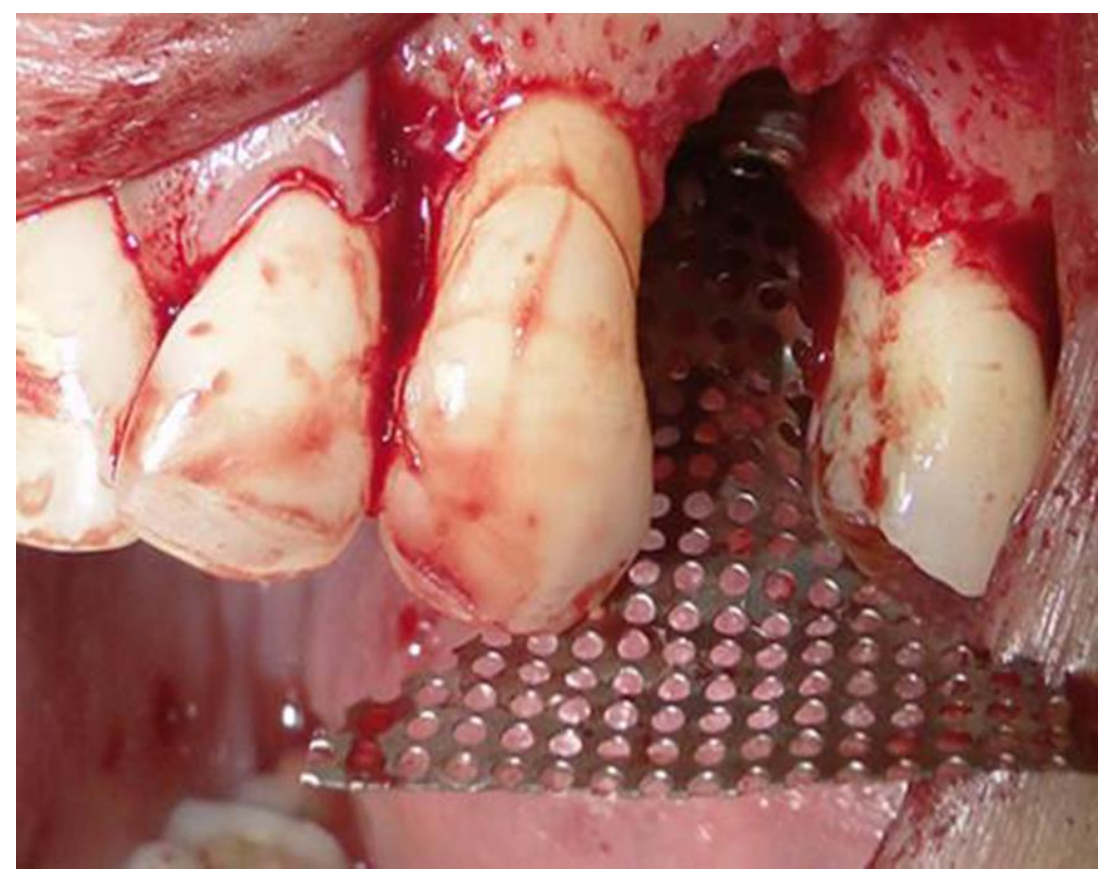

Figura 4: Adaptação da malha de titânio.

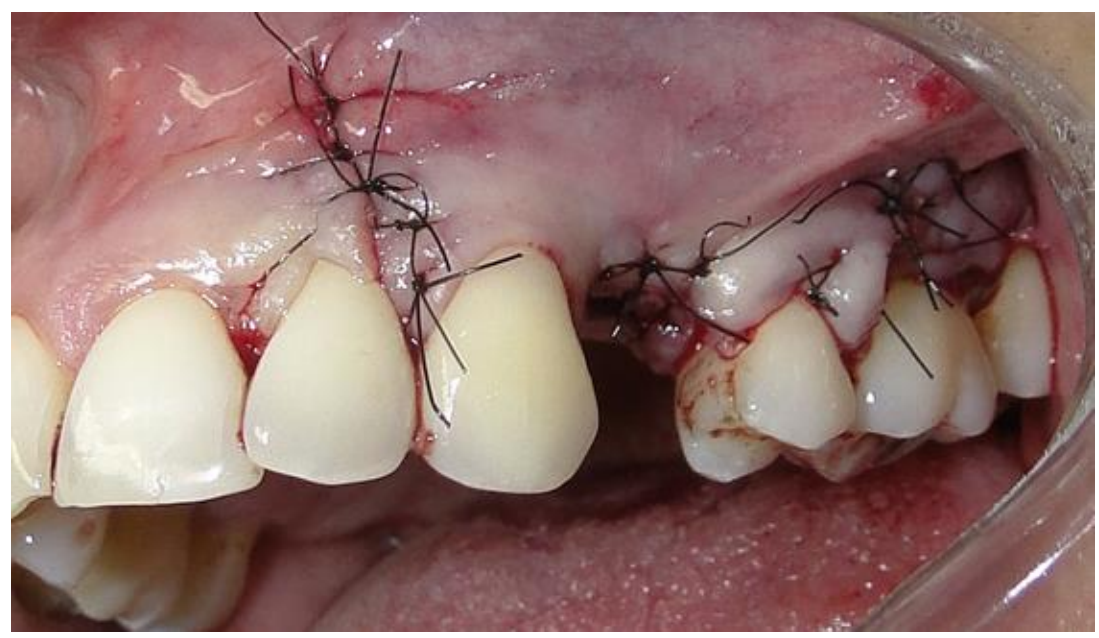

Figura 5: Sutura com fio de Nylon 5.0.

Decorridos 8 meses, o paciente foi avaliado clínica e tomograficamente, evidenciando-se sucesso na ROG. Realizou-se então o procedimento de reabertura e remoção da tela de titânio, nova colocação de membranas de PRF. Após 3 meses procedeu-se à moldagem personalizada e confecção da prótese cerâmica final (Figura 6).

Esse caso esta com acompanhamento de 36 meses (Figura 7), nesse período, o paciente não relatou queixa álgica. Na avaliação clínica não tem sido observada a presença de mobilidade do implante e de infecção; nos exames de imagem, há ausência de radiolucidez na junção osso/implante (Figuras 8). Esses fatores caracterizam o sucesso do tratamento estabelecido ${ }^{1}$. 


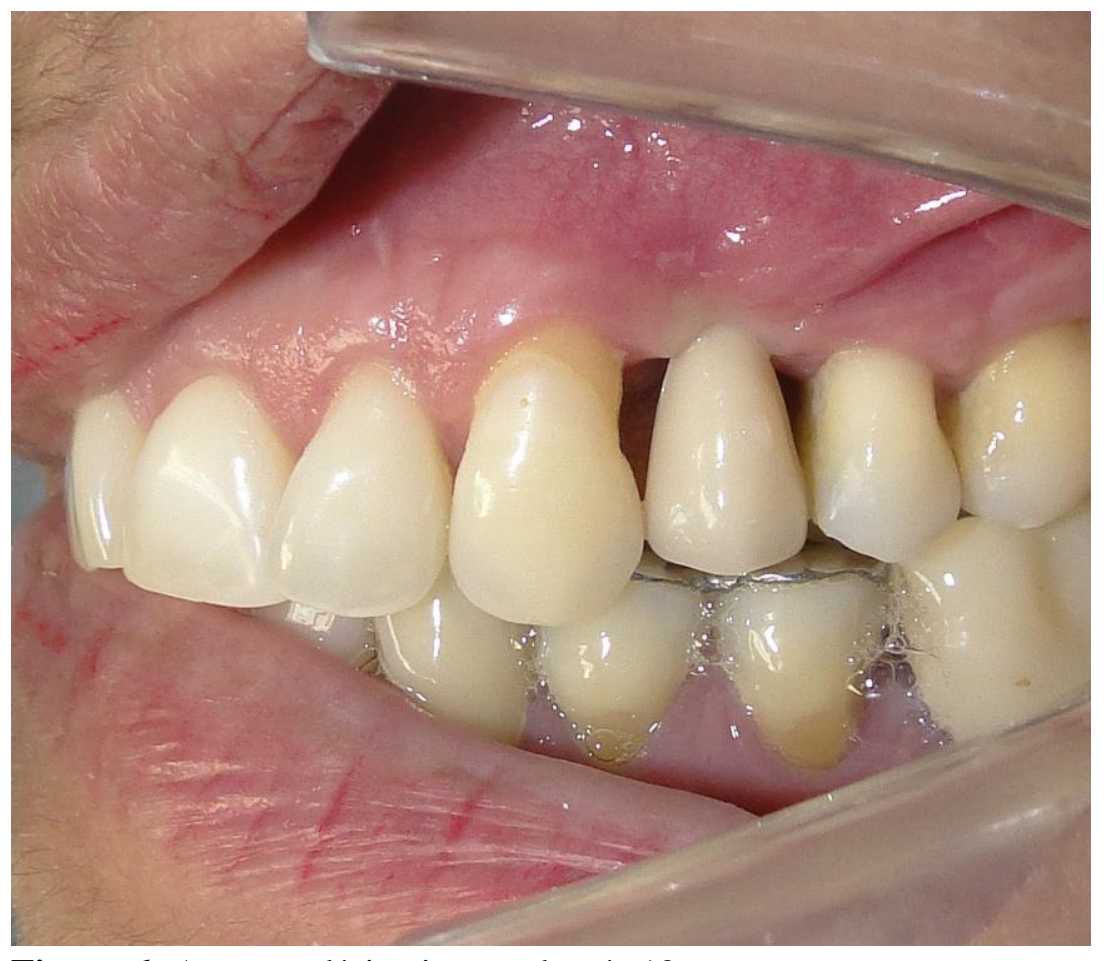

Figura 6: Aspecto clínico intraoral após 12 meses.

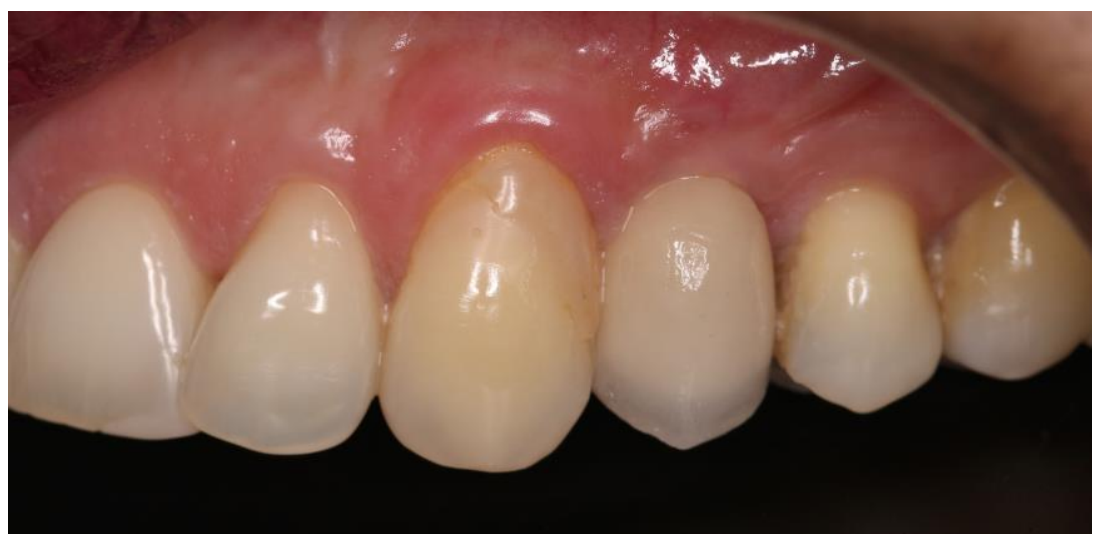

Figura 7: Aspecto clínico intraoral após 36 meses.
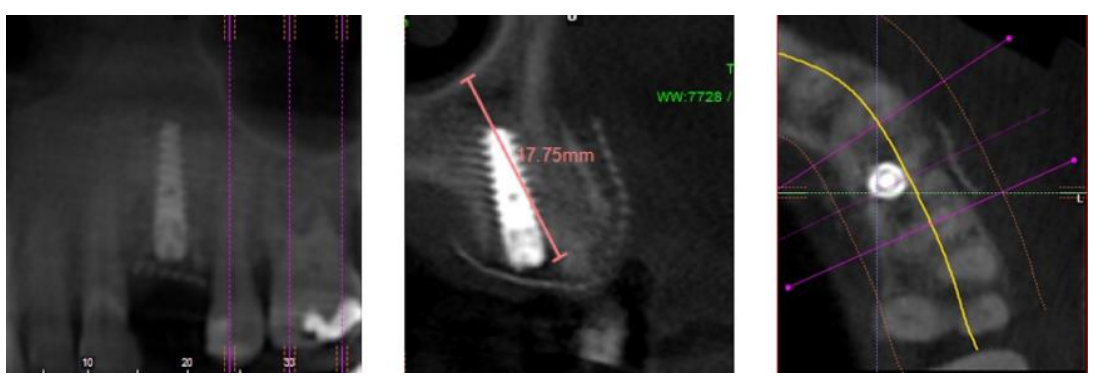

Figura 8: Avaliação tomográfica com 36 meses.

\section{DISCUSSÃO}

O objetivo do presente estudo foi avaliar o sucesso referente a implante instalado imediatamente após extração do elemento dentário com infecção periapical crônica ativa, essa técnica foi viável apresentando reabilitação satisfatória no pós-operatório.

Marconcini et al. ${ }^{18}$ realizaram um estudo com a instalação de implantes imediatos após extração de dentes com lesão endodôntica periapical, e os resultados mostraram a taxa de sobrevivência de 97,4\% após o acompanhamento de um ano. Adicionalmente, os autores relataram que a perda óssea foi aceitável nos diferentes grupos experimentais.

Estudos propuseram a instalação imediata do implante após a extração do elemento dentário, com o intuito de diminuir o processo de reabsorção óssea alveolar e minimizar o tempo de tratamento do implante. Nesse estudo foi evidenciado que a taxa de sucesso na colocação imediata é semelhante às obtidas quando o implante é mediato ${ }^{34}$.

Inúmeros autores compararam a instalação de implantes em área com ausência e presença de infecção e a maioria dessas pesquisas obtiveram resultados semelhantes para os dois sítios ${ }^{8-22}$ (Quadro 1). Esses resultados bem sucedidos podem ser explicados por eventos biológicos durante a cicatrização como os princípios biológicos, cirúrgicos, biomecânicos, a estabilidade do implante, controle de carga e a resposta inflamatória ${ }^{11}$.

Crespi et al. ${ }^{11}$ e Lindeboom et al. ${ }^{17}$ descreveram que as bactérias referentes a infecção periapical, por serem anaeróbias estão estritas ao canal radicular infectado. Dessa forma, seguindo com uma extração cautelosa do elemento dentário infectado e correto protocolo de cuidados com o alvéolo, incluindo debridamento e antibioticoterapia, a técnica de instalação imediata de implante é viável.

Além do desbridamento adequado da área infectada e antibioticoterapia, outro fator que influencia positivamente o sucesso de implantes imediatos em área infectada é a regeneração óssea guiada (ROG), devido à perda óssea geralmente se dá em resposta a infecção periapical. A ROG é realizada com uso de substitutos ósseos associados ou não a membrana colágena. Essa modalidade permite o ganho de osso marginal no implante imediato, acrescendo na estabilidade do implante.

Atualmente o PRF associado ao biomaterial em grânulos é amplamente utilizado para regeneração tecidual periodontal apresentado um ganho de tecido ósseo e mole na região, menor perda óssea marginal e alta taxa de sucesso ${ }^{35,36}$. Corroborando com as pesquisa supracitadas, nesse estudo utilizou-se biomaterial de origem bovina e a malha de titânio associado ao PRF, para reconstrução da região devido ao extenso defeito ósseo apresentando resultado favorável.

\section{CONSIDERAÇÕES FINAIS}

A instalação imediata de implantes em área comprometida pode ser um protocolo viável, desde que o profissional respeite os procedimentos clínicos adequados incluindo a limpeza meticulosa e o debridamento alveolar correto. Sempre objetivando o resultado funcional, estético e uma completa reabilitação do paciente.

\section{REFERENCIAS}

1. Buser D, Weber HP, Brägger U, Balsiger C. Tissue integration of one-stage implants: three-year results of a prospective longitudinal study with hollow cylinder and hollow screw implants. Quintessence Int. 1994; 25(10):679-86.

2. Ortega-Martinez J, Perez-Pascual T, Mareque-Bueno S, Hernández-Alfaro F, Férres-Padró E. Immediate implants following tooth extraction. A systematic review. Med Oral Patol Oral Cir Bucal. 2012;17(2):e251-61.

3. Velasco Ortega E, Jimenez Guerra JA, Monsalve Guil L, Ortiz Garcia I, España López E, Matos Garrido N. Carga inmediata de implantes insertados en alvéolos postextracción. Resultados clínicos a dos años. Avances en Periodoncia. 2015;27(1):37-45.

4. Müller A, Silva ACBR, Schmidt LTH. Implante unitário submetido à carga imediata. RGO. 2004; 52(1):27-41.

5. Sabir M, Alam MN. Survival of implants in immediate extraction sockets of anterior teeth: Early clinical results. J Clin Diagn Res. 2015; 9(6):ZC58-61.

6. Balaguer-Marti JC, Peñarrocha-Oltra D, BalaguerMartinez J, ocha-PeñarDiago M. Immediate bleeding complications in dental implants: A systematic review. Med Oral Patol Oral Cir Bucal. 2015; 20(2):e231-8.

7. Paolantonio M, Dolci M, Scarano A, D'archivio D, di Placido G, Tumini $\mathrm{V}$ et al. Immediate implantation in fresh extraction sockets. A controlled clinical and histologic study in man. J Periodontol. 2001; 72(11):1560-71.

8. Bell CL, Diehl D, Bell BM, Bell RE. The immediate placement of dental implants into extraction sites with periapical lesions: A retrospective chart review. J Oral Maxillofac Surg. 2011; 69(6):1623-7.

9. Casap N, Zeltser C, Wexler A, Tarazi E, Zeltser R. Immediate placement of dental implants into debrided infected dentoalveolar sockets. J Oral Maxillofac Surg. 2007; 65(3):384-92.

10. Crespi R, Capparè P, Gherlone E. Fresh socket implants in periapical infected sites in humans. J Periodontol. 2010; 81(3):378-83. 
11. Crespi R, Capparé P, Gherlone E. Immediate loading of dental implants placed in periodontally infected and noninfected sites: A 4-year follow-up clinical study. J Periodontol. 2010; 81(8):1140-6.

12. Del Fabbro M, Boggian $C$, Taschieri S. Immediate implant placement into fresh extraction sites with chronic periapical pathologic features combined with plasma rich in growth factors: Preliminary results of single-cohort study. J Oral Maxillofac Surg. 2009; 67(11):2476-84.

13. Deng F, Zhang H, Zhang H, Shao H, He Q, Zhang P. A comparison of clinical outcomes for implants placed in fresh extraction sockets versus healed sites in periodontally compromised patients: A 1-year follow-up report. Int J Oral Maxillofac Implants. 2010; 25(5):1036-40.

14. Fugazzotto P. A retrospective analysis of immediately placed implants in 418 sites exhibiting periapical pathology: Results and clinical considerations. Int J Oral MaxIllorofac Implants. 2012; 27(1):194-202.

15. Jung RE, Zaugg B, Philipp AO, Truninger TC, Siegenthaler DW, Hämmerle $\mathrm{CH}$. A prospective, controlled clinical trial evaluating the clinical radiological and aesthetic outcome after 5 years of immediately placed implants in sockets exhibiting periapical pathology. Clin Oral Implants Res. 2013; 24(8):839-46.

16. Khademi A, Shadmehr E, Ajami M, Rismanchian M, Razav SM. Histologic and histomorphometric assessment of implants and periapical tissues when placed in the sockets of extracted teeth, teeth with periapical lesions, and healed lesions: A canine study. J Oral Implantol. 2013;39(6):709-13.

17. Lindeboom JA, Tjiook Y, Kroon FH. Immediate placement of implants in periapical infected sites: A prospective randomized study in 50 patients. Oral Surg Oral Med Oral Pathol Oral Radiol Endod. 2006;101(6):705-10.

18. Marconcini S, Barone A, Gelpi F, Briguglio F, Covani U. Immediate implant placement in infected sites: A case series. J Periodontol. 2013; 84(2):196-202.

19. Naves MM, Horbylon BZ, Gomes CF, Menezes HHM, Bataglion C, Magalhães D. Immediate implants placed into infected sockets: A case report with 3-year followup. Braz Dent J. 2009; 20(3):254-8.

20. Siegenthaler DW, Jung RE, Holderegger C, Roos M, Hämmerle CHF. Replacement of teeth exhibiting periapical pathology by immediate implants. A prospective, controlled clinical trial. Clin Oral Impl Res. 2007; 18(6):727-37.

21. Truninger TC, Philipp AO, Siegenthaler DW, Roos M, Hämmerle $\mathrm{CH}$, Jung RE. A prospective, controlled clinical trial evaluating the clinical and radiological outcome after 3 years of immediately placed implants in sockets exhibiting periapical pathology. Clin Oral Implants Res. 2011; 22(1):20-7.

22. Villa R, Rangert B. Early Loading of Interforaminal Implants Immediately Installed after Extraction of Teeth Presenting Endodontic and Periodontal Lesions. Clinic Implant Dent Relat Res. 2005; 7(Suppl 1):S28-35.

23. dos Santos PL, de Molon RS, Queiroz TP, Okamoto R, de Souza Faloni AP, Gulinelli JL et al. Evaluation of bone substitutes for treatment of peri-implant bone defects: biomechanical, histological, and immunohistochemical analyses in the rabbit tíbia. J Periodontal Implant Sci. 2016; 46(3):176-96.

24. Grandi T, Garuti G, Samarani R, Guazzi P, Forabosco A. Immediate loading of single pos-extractive implants in the anterior maxila. J Oral Implantol. 2012; 38(1):477-84.
25. Shetye O, Shetye NK, Louis A, Roy I. Immediate implantation in an extraction socket: A review. Int $\mathbf{J}$ Contemp Dent Med Rev. 2015; Article ID 160115.

26. Agustín-Panadero R, Serra-Pastor B, Chust-Lopez C, Fons-Font A, Ferreiroa A. Immediate placement of single implant simultaneously with immediate loading in a fresh socket associated to periapical infection: A clinical case report. J Clin Exp Dent. 2015; 7(1):e175-9.

27. Peredo-Paz LG, Francischone CE, Ferreira E, Sidney R. Carga imediata em próteses unitárias pós exodontia, em áreas estéticas. 2008; 2:92-109. Rev Dental Press Periodontia Implantol. 2008; 2(1):92-109.

28. Zani SR, Alves RA, Korb SHB, Rivaldo EG, Frasca LCF. Colocação de implante imediato após exodontia: Relato de caso clínico. Odontol Clín-Cient. 2011; 10(3):281-4.

29. Albrektsson T, Brånemark PI, Hansson HA, Lindström J. Osseointegrated titanium implants. Requirements for ensuring a long-lasting, direct bone-to-implant anchorage in man. Acta Orthop Scand. 1981; 52(2):155-70.

30. Wilson TG Jr. Guided tissue regeneration around dental implants in immediate and recent extraction sockets: Initial observations. Int J Periodontics Restorative Dent. 1992; 12(3): 185-93.

31. Garber DA, Salama MA, Salama H. Immediate total tooth replacement. Compend Contin Educ Dent. 2001; 22(3):210-8

32. Tabrizi R, Azizi M. Mesiodistal bone loss of fresh socket placed implants and delay placed implants at the anterior of the maxila. Int $\mathbf{J}$ Oral Implantol Clin Res. 2013; 4(2):63-7.

33. Waasdorp JA, Evian CI, Mandacchia M. Immediate placement of implants into infected sites: A systematic review of the literature. J Periodontol. 2010; 81(6):801-8

34. Álvarez-Camino JC, Valmaseda-Castellón E, GayEscoda C. Immediate implants in fresh sockets associated to periapical infections processos- A systematic review. Med Oral Patol Oral Cir Bucal. 2013; 18(5):e780-5

35. Lee JW, Kim SG, Kim JY, Lee JC, Choi JY, Dragos R, et al. Restoration of a peri-implant defect by platelet-rich fibrin. Oral Surg Oral Med Oral Pathol Oral Radiol. 2012;113:459-63.

36. Boora P, Rathee M, Bhoria M. Effect of platelet rich fibrin (PRF) on peri-implant soft tissue and crestal bone in one-stage implant placement: a randomized controlled trial. J Clin Diagn Res. 2015; 9(4):ZC18-21.

\section{CONFLITO DE INTERESSES}

Os autores declaram não haver conflitos de interesse.

\section{AUTOR PARA CORRESPONDÊNCIA}

Pâmela Letícia dos Santos

pamelalsantos@hotmail.com

Submetido em 28/02/2018 Aceito em 27/03/2018 